\title{
A Bio-inspired approach for boosting innovation in the Separation Technology Sector
}

\author{
Alessandro Bianciardi*, Gaetano Cascini \\ Politecnico di Milano - Department of Mechanical Engineering - Campus Bovisa Sud - via La Masa 1, \\ 20156 Milan, Italy \\ *corresponding author: Tel: +357-99458262 - email: alexbiancia@hotmail.com
}

\section{Highlights}

- A Biologically-Inspired Design method for sectoral innovation based on the organisation of biological information in function-oriented databases;

- Extracted bioinspired design principles for innovating separation technology;

- Prototype of passive desalination technology inspired by Mangroves ecosystem;

- Prototype of antibacterial surface inspired by shark's skin and the epithelial cells of a teleost (fish).

\begin{abstract}
Because of its size, high segmentation within the global market and challenges driving its development, the separation technology sector Because of its size, high segmentation within the global market and challenges driving its development, the separation technology sector could benefit from a bio-inspired approach to innovation to create more efficient and sustainable solutions. The potential for bio-inspired innovation is still largely untapped and Biologically-Inspired Design (BID) methods and tools are still largely underutilised, especially within the industry.
\end{abstract}


A new BID method, called Guild-Based (GB) BID, is proposed to create a database of a large set of biological solutions - identified by a function - where biological information is structured to be more effective and usable within the industrial environment.

A database for the separation technology sector has been set up and populated with 118 relevant biological solutions responding to the main function "to separate". The database has been utilised to generate several clusters of solutions depending on the level of detail of the formulated problem. In particular, these include: broad design principles of separation; taxonomies of biological solutions for specific separation problems; and novel design concepts for two specific separation technologies (a desalination technology and an antibacterial surface).

Furthermore, because of a large dataset of biological solutions, the possibility of determining the frequency of occurrence of specific separation strategies in nature can trigger reflections on the impact of existing separation technologies and taking decisions on future related R\&D paths.

More tests need to be conducted in the industrial environment; however, the results achieved so far indicate that the method proposed can indeed be instrumental to generating innovative ideas of interest to the separation technology sector.

\section{KEYWORDS}

Bio-inspired innovation, Biologically-Inspired Design, Separation technologies, desalination, ideation.

\section{Introduction}


Filtration/separation technologies are everywhere in industrialised countries. As a global business segment approaching $\$ 85$ billion in annual revenues, the separation technology sector generally stays below the average consumer's radar because the product they purchase is generally not a filter (1). What consumers buy include beverages that have been filtered, cars that contain several filtering devices, and tickets to fly in planes whose jet fuel, hydraulic fluids and cabin air have been filtered.

The separation technology sector delivers to the following major markets and their segments (1):

- $42 \%$ Water/Wastewater: municipal and industrial water and wastewater, consumer/commercial water.

- $20 \%$ Industrial Processes: chemical processing, oil and gas, fluid power, microelectronics, pulp and paper, power generation.

- $13 \%$ Transport: automotive, heavy vehicle/off-road, aviation, aerospace.

- $13 \%$ Life Science: pharmaceuticals, biotech manufacturing laboratory filters, medical devices, in-vitro diagnostics, food and beverage industry.

- $12 \% \mathrm{HVAC} /$ Pollution control: residential/commercial HVAC, medical and industrial controlled environments, industrial pollution and exhaust gas control.

The following challenges are currently driving innovation in separation technologies $(1,2)$ :

- Population growth and rapid urbanisation will increase demand, requiring increased productivity and improvements in manufacturing efficiency and infrastructure dependent on separation technology.

- Natural resource scarcity and climate change will make it increasingly difficult to supply an evergrowing population with clean water. This will increase the use of desalination technologies and the recycling and reuse of wastewater on a consumer, commercial, and industrial scale.

- Transformative advances in healthcare that utilise filtration and separation rather than chemical technologies as there is a greater increased focus on a cleaner environment. 
- The race to zero emissions and zero discharge. Filtration and separation are among the major enabling technologies for achieving this through purifying, recycling and reusing processes.

- Continuous improvements in digital technology. Smaller and more sophisticated computer circuits will require more advanced filtration systems.

The sector's focus is mainly on researching and innovating filtration media to enhance separation efficiency; for instance, by using nanofibers, mixing nonwoven filters with absorbent materials (e.g., activated carbon), and introducing charge imbalances or functional groups on filter surfaces (3).

Considering the range of applications of separation technologies, the growing importance of this sector to tackle global challenges and its current paths of innovation, there seems to be ample opportunity for diversifying these paths with new ideas; ideas that could be generated following bio-inspired approaches. Several research studies are ongoing around bio-inspired separation processes, mainly focusing on enhancing membrane performances (for water treatment, oil/water separation and desalination). Some research focuses on embedding superficial patterns of micro/nano structures (roughness) which imitate skins and cuticles surfaces of organisms; patterns that provide properties such as superhydrophilicity/phobicity or super-oleophobicity. Some other research focuses on improving membrane's separation capacity emulating cellular membrane's water channels (called aquaporins) (reviews are provided in (4-6)). Research in bio-inspired functional surfaces is one of the most prolific biomimetic topics explored so far because of the potential for solving several problems (for instance, in tribology, medicine, and the textile industry, to mention a few). However, to the best knowledge of the authors, there are no reviews of already existing bio-inspired solutions on the separation technology market. Therefore, it seems that the potential for bio-inspired innovation in separation technology is still largely untapped.

In this context, this paper proposes an original biologically-inspired design method and a supporting database of biological solutions that can support the generation of novel ideas in the separation technology sector. The method has been tested in several projects and open workshops and is illustrated 
here by means of two case studies; one relates to a mangrove-inspired passive desalination process, and the other to an antibacterial surface inspired by shark's skin and the epithelial cells of a teleost fish's gills. The paper is therefore structured according to the following sections: section 2 proposes an overview of Biologically-Inspired Design approaches and clarifies the specific objectives of this research. The method and application database are described in section 3, while section 4 presents the results of the testing and validation process. Following this, section 5 illustrates the above-mentioned case studies with details on the advanced performance achieved by the prototype solutions. The closing section also reflects on the limitations of the contribution emerging from this study and opportunities for further development.

\section{Bio-inspired approaches for the generation of innovative ideas}

\subsection{Biologically-Inspired Design approaches}

Over the last two decades, increasing attention has been given to bio-inspiration, the process of becoming inspired by strategies and mechanisms used by living systems in order to solve problems $(7,8)$. Since the operating principles of living systems can be considered intrinsically sustainable (use of renewable energy, reuse and upcycling of waste, use of eco-friendly materials, use of locally available resources, adaption and resilience to crisis, etc.)(9), taking inspiration from them may result in innovations with a higher degree of sustainability.

The term Biologically-Inspired Design (BID) is utilised throughout this study to refer to a cluster of structured methods and tools for ideas generation, which belongs to the broader class of Design-byAnalogy approaches. In the case of BID, the analogies come from the domain of biology. Using analogies from the natural world could help overcome design fixations and stimulate divergent thinking, thus leading to the generation of unusual and more innovative ideas (10). 
Like several other design approaches, BID can be exploited following two alternative kinds of processes: solution-driven or problem-driven. A solution-driven approach means when initially identified biological information inspires the solution to one or more specific problem(s) identified a posteriori; problem-driven approaches start with a problem that needs to be solved and a targeted search into biological knowledge which can inspire a solution. A BID problem-driven approach can be developed through the steps (11) as per Table 2-1:

\begin{tabular}{|c|c|}
\hline $\begin{array}{l}\text { Problem-driven } \\
\text { approach }\end{array}$ & Description \\
\hline $\begin{array}{l}\text { 1. Problem definition/ } \\
\text { analysis }\end{array}$ & $\begin{array}{l}\text { Selection of the problem to be solved and defining it further through functional } \\
\text { decomposition. }\end{array}$ \\
\hline 2. Reframe the problem & $\begin{array}{l}\text { Redefining the problem using broadly applicable biological terms. Asking the question: "How } \\
\text { do living systems perform this function?" }\end{array}$ \\
\hline $\begin{array}{l}\text { 3. Biological solution } \\
\text { search }\end{array}$ & $\begin{array}{l}\text { Selection of biological model(s) of interest. Find solutions relevant to the biological problem } \\
\text { with various techniques, consulting biologists or open-access databases such as Asknature.org. }\end{array}$ \\
\hline $\begin{array}{l}\text { 4. Definition of the } \\
\text { biological solution }\end{array}$ & $\begin{array}{l}\text { The biological information is refined to some working principles, strategies or representative } \\
\text { models that explain the biological solution and could be further transferred to the target } \\
\text { application (12). }\end{array}$ \\
\hline 5. Principle extraction & $\begin{array}{l}\text { After a solution is understood, relevant principles are extracted into a "solution-neutral" form, } \\
\text { which requires a description in non-biological terms that removes as many specific structural } \\
\text { and environmental constraints as possible. }\end{array}$ \\
\hline 6. Principle application & $\begin{array}{l}\text { After the principle is extracted from the biological solution, designers transfer the principle into } \\
\text { the new domain. This transfer involves an interpretation from one domain space (e.g. biology) } \\
\text { into another (e.g. mechanical engineering) by introducing new constraints to the biological } \\
\text { problem (11). }\end{array}$ \\
\hline
\end{tabular}

Table 2-1: Steps of the Problem-driven approach. From(11)with description made by the authors. 
BID methods and tools have been developed by different research groups and organisations to address one or all the steps of the process. Various recent studies (13-15) have compiled reviews of these aspects of BID.

Central to the BID process is the identification of the function(s) the solution is expected to perform to address the problem. Therefore, the function becomes the "bridge" between the domain of biology and the domain of the problem, between the biological strategy and the innovative solution.

Identifying, extracting and processing biological information to be useful to innovators are the major costs associated with a BID process. Automatised data mining tools for BID have been proposed (16) though their effectiveness and applicability in the industrial environment have not been recorded. Some BID methods propose models to represent biological processes and structures $(17,18)$, which however may not be user-friendly to non-biologist users $(12,14)$. Others (such as Asknature.org) provide only texts extracted from articles, books and other sources of biological knowledge. Due to the cost of gathering meaningful biological information and its organisation, existing and accessible repositories either lack quantities of biological solutions or lack in the quality and detail of biological information to be useful in addressing a broad spectrum of problems. For instance, some accessible repositories contain between 30 to 140 entries of biological solutions from different ecosystems and carry out different functions (18-20); therefore offering a limited range of potential solutions for each function. The largest repository accessible to the public is Asknature.org, with more than 1700 biological strategies categorised according to a taxonomy of biological functions, i.e. the Biomimicry Taxonomy (21). However, the information structure is not homogeneous and the level of detail varies considerably among the biological entries.

\subsection{Diffusion of bio-inspired innovation}

While the general concept of bio-inspiration is already widespread, the use of BID methods in the industry is not. 
Few studies and statistics are available on the diffusion of bio-inspiration at different stages of the innovation process. Some authors have provided evidence of an exponential increase in published biomimetic research in the last fifteen years $(22,23)$. The BioM innovation database $(24)$ produced the first worldwide analysis of products deriving from a BID process. At the time of publication, the BioM innovation database contained 380 cases initially identified through a search in popular literature, but this has reportedly not been updated since then (25). Of the 380 cases, the stage of development of 379 was identified. Out of these, 116 were identified as being commercially available to the general consumer, 220 were in development (mostly at a prototype stage) with limited availability, 29 were still unpatented concepts (or patent-pending), and eight were discontinued after having been commercially available.

A recent study of the application of biomimicry in nordic countries (26) highlighted that, out of 100 organisations/professionals involved in biomimetic related activities, almost half (53\%) were categorised as academic research and development and one third (31\%) fell into the category of industry. Within the latter, the sectors with the highest percentage of biomimetic activity were consulting companies (20\%), urban planning and architecture (17\%), material development (14\%), product development (12\%) and water and sanitation (12\%).

It is therefore highlighted a persistent lack of utilisation of BID in the industrial sector, which could, on the other hand, assist in generating new ideas for future innovation.

\subsection{The aim of the research}

Based on the aforementioned need for innovation in the separation technology sector (see 2.1) and the current low penetration of BID approaches within the industrial sector (see 2.2), the main objective of this study is to enhance the capacity of the separation technology industry to generate new ideas for radical and incremental innovation through bio-inspired approaches. 
The specific contribution of this research is, therefore, to provide a new instrument, a BID method, and a supporting database to achieve the aforementioned objective.

The instrument has been developed to optimise the process of organising biological knowledge to make the BID process more effective in generating ideas for problems with different levels of abstraction. The instrument possibly yielded solutions that are more cost-efficient and more approachable not only by typical ideas developers, but by actors relevant to the overall innovation process (e.g., managers, production operators, marketing) as illustrated in the following sections.

\section{Guild-Based BID method}

\subsection{Methodological approach}

The BID method proposed has been developed through the following general methodological approach:

- The formulation of a classification of biological information, which can contribute to the BID process of ideas generation. This was done based on the existing literature on BID methods and tools, reviewing their structures, purposes, organisation of information $(11,12,17,18,27-30)$ and limitations identified $(12,14)$. This framework for biological information has been named the Guild-Based (GB) BID method.

- Based on the above, a GB-BID database was set up with biological information relevant to the separation technology sector as the area of application to show the potential and advantages of the proposed approach.

- The database was tested and validated through:

i) the development of case studies of bio-inspired solutions for the separation technology sector, following the step-wise problem-driven approach outlined in Table 2-1 but using the GB-BID database to implement steps 3 and 4; 
ii) ideas generation workshops with different target groups to test usability by third parties.

The second part of the validation as described in ii) is not reported here and will be presented in further publications focused on usability aspects of the proposed method.

\subsection{Guild-Based BID method}

The BID method has been named Guild-based because it was also inspired by a biological analogy:: the concept of a biological guild or functional group. A guild can be defined as a group of species of organisms providing a similar function to the ecosystem or competing for the same resource within an ecosystem e.g., folivores such as elephants, scavengers, nitrogen fixing organisms, and pollinators (31). Interactions within a guild and between guilds are processes contributing to the evolution of species by generating new and adaptive phenotypes (successful traits in a species transmitted through generations)(31-34). The term guild-based is also utilized in the domain of biology. It refers to methods to determine ecosystem's behavior and conditions by assessing the abundance and diversity of guilds in ecosystems utilised the behaviour $(35,36)$. Nevertheless, in this study, the term is used with a different intent. This biological analogy has been in fact broadly transferred to the domain of design, as described in Table 3-1.

\begin{tabular}{|l|l|}
\hline \multicolumn{1}{|c|}{ Biology } & \\
\hline A Guild/Functional Group & An industrial sector (e.g., automotive, solar energy, filtration) \\
\hline Specific function within the ecosystem. & Specific products on the market: cars, PV solar panels, filters \\
e.g., scavenging for reusing resources & \\
\hline Competing for specific resources: leaves, flowers, sunlight & Competing for resources in specific market segments \\
\hline
\end{tabular}

Table 3-1: Biological analogy transfer: from the biological guild to the industrial sector

The GB-BID method proposes to gather biological knowledge and organise it to set up databases (the tool). Each database contains biological solutions related to a specific main function for generating new solutions within a specific industrial sector for which this function is relevant. For instance, firms that work on 
innovating energy storage devices may set up and consult a GB-BID database based on the function "store energy", where biological solutions related to that function are proposed. The use of a single GB-BID database could inspire radically new design concepts, as well as helping to improve incrementally existing products.

Figure 3-1 proposes a schematic representation of the GB-BID database structure with its categories of information.

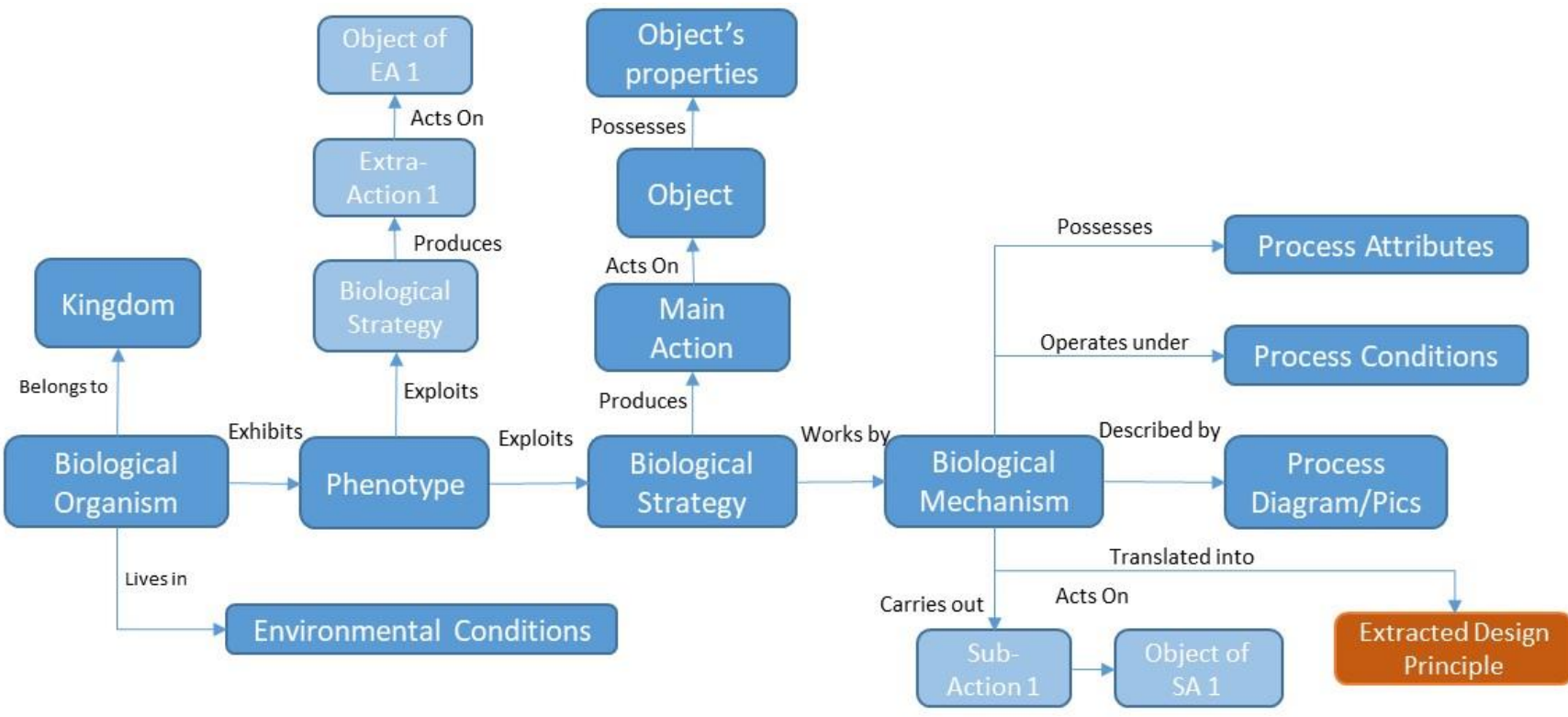

\footnotetext{
$\rightarrow$ Operative Connection between two categories of information

Category of information from biological solution

Information not always existing present in biological solution

Informationgenerated by the user based on biological information
}

Figure 3-1: Categories of Information in the GB-BID database (blue boxes). The light blue boxes denote information that is not necessarily present in the biological solution. The arrows highlight operative connections between subsequent categories of information. The orange box represents the extracted design principles, which can be generated from biological information. (SA) Sub-action, (EA) Extra action. 
For some categories, a single field in the database could be enough; whereas for others, for instance, process attributes and conditions, several fields may be needed and can be customised according to the specific sector considered. Table 3-2 below presents an example of a possible database entry.

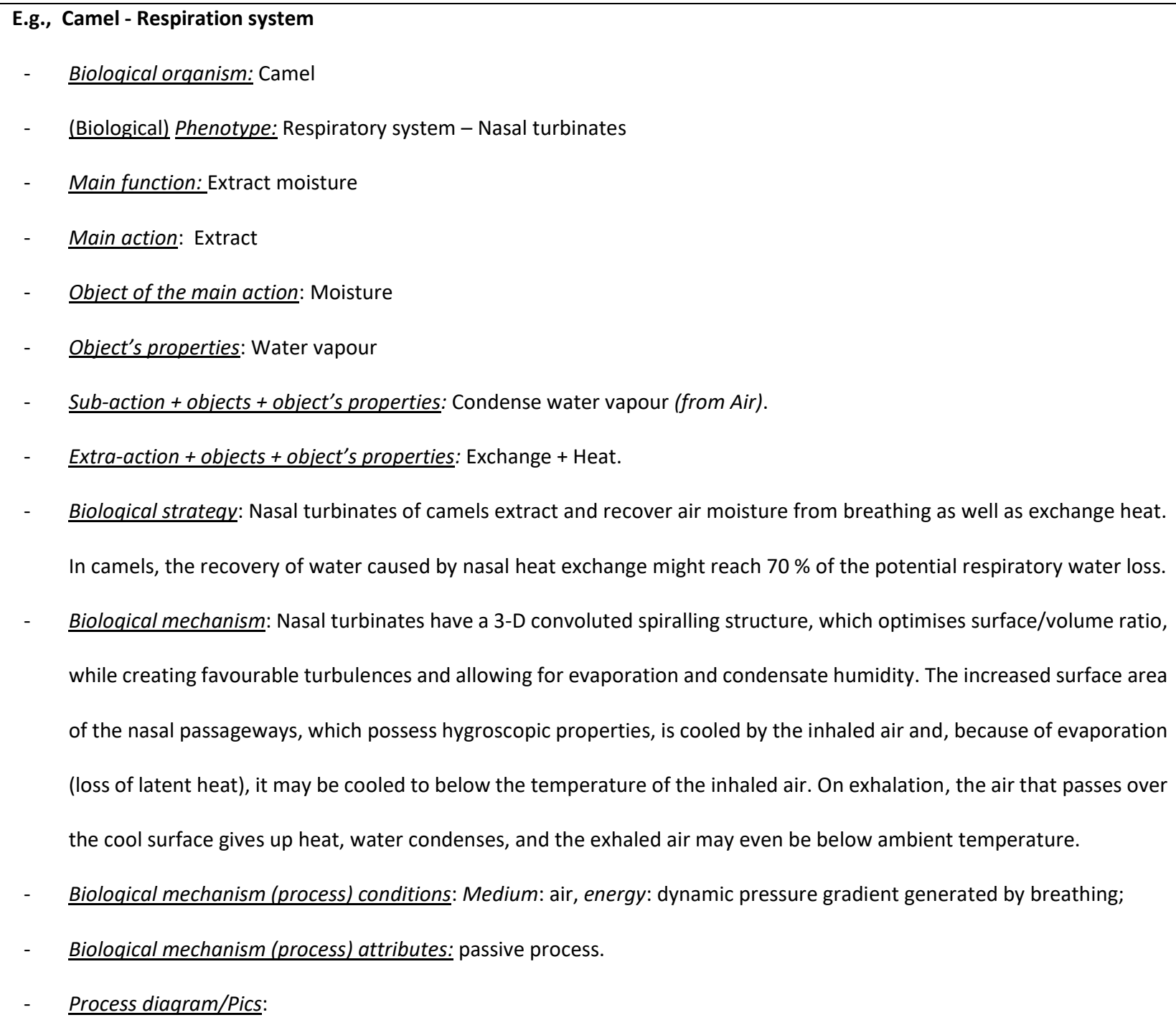




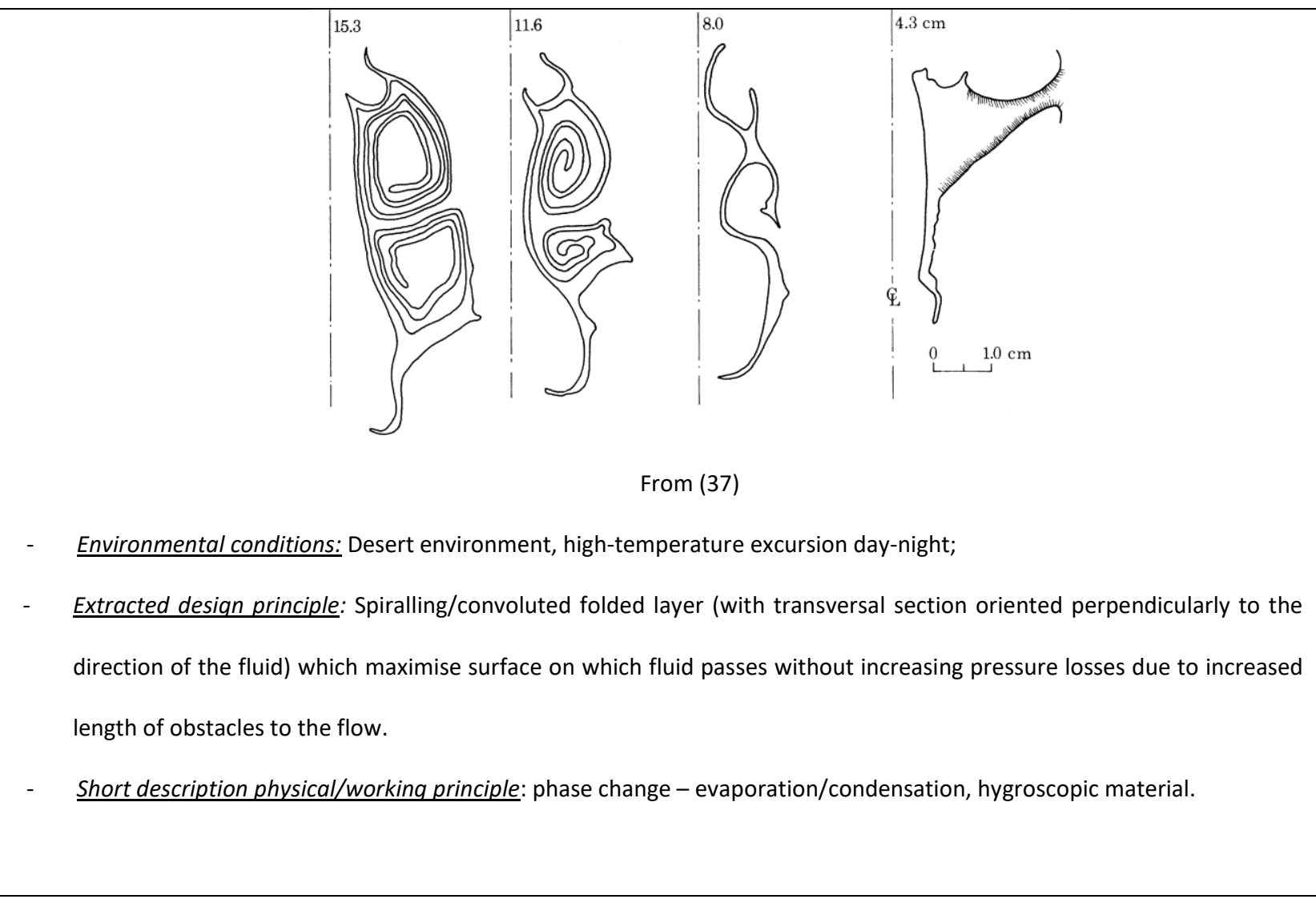

Table 3-2: Example of possible entry in a GB-BID database

Building a database of several phenotypes (biological solutions) makes it possible to determine the frequency of occurrence, within the database, of similar biological strategies and/or mechanisms common to different phenotypes but solving a similar problem. This frequency has been named "robustness". The higher the frequency, the higher its robustness. Higher robustness within a GB-BID database could point at a mechanism that evolution considered more suitable/successful to solve that problem; this is because it reappears several times, in different organisms, and maybe in different contexts, scale and operating conditions. From the point of view of the innovation process, it could be an indication that:

- this specific strategy/mechanism works well because it passed the test of Natural Selection not once, but several times, in different periods, places, and stages of the evolutionary process;

- $\quad$ it is potentially transferable and scalable to different contexts. 
Increasing the number of entries in the database with more phenotypes deploying different biological mechanisms would allow refining the value of robustness and its reliability.

In order to allow the replication and utilisation of GB-BID databases, the following paragraph provides a detailed description of the categories of information, as shown in Figure 3-1:

- Biological organism: the organism whose phenotype carries out the main function and which is classified in the biological taxonomic classification system (38). This category also includes superorganisms: an organism consisting of many individuals working together as a single functional unit (e.g., ants colony, siphonophorae) as well as ecosystems (e.g., mangroves, salt marshes,) as long as the addressed function can be considered implemented at that biological level.

- Kingdom: the biological kingdom the organism belongs to according to the biological taxonomy.

- (Biological) Phenotype: other BID methods usually refer to this category of information as "biological system" $(39,40)$. It is proposed to use the term "phenotype" instead. Phenotype is defined as the observable characteristic or trait of the organism (organ, part of an organ, structure, internal process, behavior and product of behavior) carrying out the function. In fact, a complete organism itself could be considered a phenotype composed of several phenotypes.

- Main function as: main action + object of the main action: this definition follows TRIZ terminology for Function Statement: "the subject (in this case, the phenotype) performs an action on an object where the action is a verb" (41). Main action: It is represented by a verb. object of the main action: the entity upon which the system acts through the function. For instance, referring to the functions above, objects could be: particles, molecules, fluid, etc.

- Object's properties: features characterising the object upon which the system acts through the function (e.g., particles of diameter ranging from 0.1-3 mm). 
- Sub-function as: Sub-action + object: the biological solution may be a complex combination of subprocesses with their own function, object and the object's properties. For instance, in the process: "to separate particles regulating flow regime", the main function + object is "to separate particles" and sub-function + object is "to regulate flow". Sub-functions are relevant because they can be the bridge to solve other problems that do not relate directly to the main function.

- Sub action object's properties: features characterising the object of the sub-function.

- Extra-function as: extra-action + objects: when studying biological structures and processes, it may result that a certain phenotype evolved to carry out multiple functions - for instance, the dermal denticles of the skin of a shark can regulate drag, be oleophobic in water and prevent bacterial colonisation $(42,43)$. Whenever identified, this multi-functionality can be recorded in the database as extra-function and be utilised, as the sub-functions, to connect with other GB-BID databases or solve other problems.

- Extra-action object's properties: features characterising the object of the extra-function.

- Biological strategy: a narrative describing how the function is achieved by the phenotype (27). The strategy shall contain references to the main function and refer to the biological name of the structure/process/behavior, which allows it to achieve its function. For instance: "the lotus leaf stays dry and clean because surface micro-roughness gives it super-hydrophobic properties". Proving this high-level abstraction of the biological solution would allow already extracting design principles, for instance: "self-cleaning surface by super-hydrophobicity provided by micro-roughness".

- Biological mechanism: a narrative describing how the biological strategy works to achieve the function. The concept of the mechanism is explained in detail, in biological terms. As "mechanism" in biology refers to the causal mechanism of a phenomenon: "A step-by-step explanation of the mode of operation of a causal process that gives rise to a phenomenon of interest. Entities, activities, and organisational features are part of the causal mechanism for $P$ (where $P$ is the phenomenon of 
interest) if and only if they are relevant to the explanation of $P^{\prime \prime}$ (44). Mechanisms occur on the level of a structure, process, or interactions within the environmental system as a whole (27). The mechanism could be the description of geometries of a structure, of processes, of behaviours or a combination of them, as long as they are relevant to the explanation of the Biological Strategy. The description can be enriched with details such as materials, dimensions and other properties. In Engineering Design terminology, the Biological mechanism could be associated with the working structure as a combination of several working principles (45).

- Biological mechanism's (or process) conditions: operating conditions within which the biological mechanism carries out the function. This type of information may be expressed by several fields of the database depending on the process and the specific requirements the solution to the technical problem has to fulfil. For instance, in the case of a separation process, conditions could include the type of fluid or medium where the process occurs (e.g., water, air, blood) and its properties, such as its Reynolds number, fluid velocity, temperature, salinity. Also, the energy source available for fuelling the mechanism could be considered within this type of information.

- Biological mechanism's (or process) attributes: together with its operating conditions, some attributes of the mechanism could also be important, such as the spatial scale at which it operates (by indicating the scale such as: $\mathrm{nm}, \mu \mathrm{m}, \mathrm{mm}, \mathrm{cm}$, etc.) and if it operates passively (exploiting free energy available in the environment) or actively (utilising metabolic energy for instance).

Both biological mechanism (process) conditions and attributes are relevant because they allow the selection, within the database, of the biological solutions, which may operate more closely to the technical problem's requirements and, therefore, possibly inspire more relevant technical solutions. This information also allows for reflecting on difficulties in scaling certain biological mechanisms up or down and on the potential for low-energy consumption technical solutions (derived from passively operating biological solution). 
- Process diagram/Pics: a schematisation of the biological mechanism through infographics, drawings, diagrams, photos and all visual information that can help in understanding the biological mechanisms beyond textual information. Efforts should be made to provide visual information, as this is valuable for the participation of non-biologists and non-technicians in the idea generation process.

- Environmental conditions: environmental conditions where the organism and its phenotype operate. This information can complement the ones provided by the biological mechanism conditions to identify specific patterns of biological solutions according to specific environmental conditions that could reflect the environmental conditions of the technical problem. For instance, biological solutions operating in seawater or a desert environment, an artic environment, high altitude, etc.

- Extracted design principle: design principle extracted from the biology mechanism and explained in non-biological terms. This is the key information that will be used for generating ideas. Different existing methods could be used for this process and it is not in the scope of this research to elaborate on them. For the purpose of this research, the extracted principles utilised for the testing and validation process have been identified by the authors rewriting the biological mechanisms without using biological terms but aiming at staying true to the science.

In addition, the following categories derived from the information above could be added to the database:

- Short description of the physical/working principle: this should include the physical and working principles behind the mechanism described in non-biological terms. This category of information is helpful to cluster solutions according to those principles when they are a requirement in the search for technical solutions.

- References: list of scientific articles and other documentation utilised to extract the information to populate the database entries. 


\subsection{How to build up the GB-BID database}

This research is not limited to proposing the GB-BID database and its implementation in the field of separation, but also intends to make it possible to replicate by third parties who wish to adopt the same approach for other sectors. For this purpose, this section describes in detail how to build a GB-BID database. It is also worth emphasising that this is the approach followed by the authors and it is not necessarily the only way to do it.

The first step to creating a GB-BID database is the identification of the main function. Once this has been identified in terms of main action (a verb) and its object, from the "problem identification" phase, the related database can be populated in the following manner:

1. Search into the Biomimicry Taxonomy of Asknature for that action and/or its synonyms;

2. Introduce those verbs into Wordnet (wordnet.princeton.edu) to seek further synonyms;

3. Review the results from Wordnet removing what is considered irrelevant or not coherent with the main action;

4. Check the results against the NIST Functional Basis for engineering design (46).

This process allows drafting a long list of verbs compatible with both biological and design domains.

The search into the domain of biology can start from Asknature, querying that database not only with the verbs derived from the Biomimicry Taxonomy but also nouns related to the process, e.g., (to) "filter" and "filtration", or "separation". Once a list of biological strategies has been identified, the search can be refined by: (i) Exploring the scientific references provided by Asknature; (ii) Exploring additional references derived from the previous ones or found through in search engines using specific keywords; (iii) Consulting biologists.

For the purpose of this research, a simple spreadsheet of MS Excel was used to store the information according to the fields of the database. In doing so, the database can be consulted by filtering multiple 
fields. Based on the problem to be addressed and its level of abstraction, the selection of relevant database records can be made in different ways. Here are some examples:

- By main function (action+object): e.g., dissipate energy;

- By main function and the object's properties: e.g., dissipate thermal energy;

- By main function, the object's properties and process attribute(s): e.g., dissipate thermal energy passively;

- By main function, the object's properties, process attribute(s) and condition(s): e.g., dissipate thermal energy passively in water;

- By a short description of the mechanism: e.g., dissipate heat by increasing surface/volume ratio. The database can be consulted individually or utilised in ideas generation workshops with multidisciplinary teams guided with appropriate ideas generation methods (47).

The database can also be helpful for a solution-driven approach, where selecting individual phenotypes and deepening the knowledge of the biological mechanism helps determine which problem it could solve.

\section{Test and validation for the separation technology sector}

Given the high potential of exploiting bio-inspired solutions in the separation technology sector, the testing and validation of the proposed GB-BID method has been carried out focusing on the main function "to separate" and setting up the related GB-BID database of biological solutions.

The database has been utilised in several case studies to provide evidence that having a GB-BID database with multiple entries related to the main function of sectoral interest allows for the generation of several clusters of solutions, depending on the level of detail of the formulated problem. In particular: 
- Overarching biological principles addressing broad problems common to the whole sector. For the industry of separation technology, they may address problems such as: how to separate solids from liquids? How to avoid clogging of membranes? How to optimise the flow dynamics in the separation process? These can set the path for new studies of radically innovative concepts (hereby defined as Sector level case studies).

- Biological solutions addressing more specific problems of certain separation processes. For instance: how to separate micro-particles from liquids? How to repel oil? How to extract moisture from the air? These questions can inspire new processes and technology, as well as support the evaluation of design concepts, products and identify research paths. Did nature develop a similar concept/process? If yes, under which conditions does it operate? If not, is it worth continuing to pursue it? How did nature solve a similar problem? (hereby defined as Sub-sector level case studies).

- Highly contextualised biological solutions can inspire novel ideas for products applied to specific contexts. For instance: how to design a filter to remove microplastics? How to separate oil from water flowing in a pipe? How to make a membrane surface self-cleaning? (this being a problem of separation at solid/liquid, solid/air interfaces) How to desalinate seawater? (hereby defined as context-driven level case studies).

Exploring filtration/separation manuals and other related publications e.g., (48), the GB-BID database's structure as per Figure 3-1 has been customised for the main function to separate, including the fields as per Table 4-1.

\begin{tabular}{|c|l|}
\hline Field in the database & \\
\hline Main Object - & Description of what needs to be separated from the main medium (the retentate in case of filtration). \\
What is Separated & E.g., particles (from water).
\end{tabular}




\begin{tabular}{|c|c|}
\hline Field in the database & Description \\
\hline Medium & Process condition: the medium (fluid) where the function is carried out: water, air, blood, mucus, etc.. \\
\hline $\begin{array}{l}\text { Information about the } \\
\text { separated }\end{array}$ & $\begin{array}{l}\text { Object properties: additional information about the elements separated. Size/density/density } \\
\text { variability/materials, etc. (e.g., particles of diameter ranging from } 0.1-3 \mathrm{~mm} \text { ) }\end{array}$ \\
\hline $\begin{array}{l}\text { Context of Sub/Extra- } \\
\qquad \text { action(s) }\end{array}$ & $\begin{array}{l}\text { Process condition: description of context of the sub or extra function(s) (e.g., Dermal denticles on shark's } \\
\text { skin reduce drag. The context could be: "water"). }\end{array}$ \\
\hline $\begin{array}{l}\text { Short description of } \\
\text { mechanism }\end{array}$ & $\begin{array}{l}\text { From the biological mechanism, a short description of the working principle is provided including some } \\
\text { of its features which could be of interest to the sector (e.g., cross-flow filtration with flow reversal, } \\
\text { hydrosol trapping). }\end{array}$ \\
\hline Separation Principle & $\begin{array}{l}\text { A short definition of the separation principles. This allows filtering records according to separation } \\
\text { principles and explores different mechanisms nature utilises to carry them out (e.g., phase change, } \\
\text { surface dead end).) }\end{array}$ \\
\hline Active/ Passive & $\begin{array}{l}\text { Process attribute: Active: energy provided by the organism to carry out function; Passive: takes } \\
\text { advantage of free energy available in the external environment. }\end{array}$ \\
\hline Scale & $\begin{array}{l}\text { Process attribute: the scale of the elements separated from the main fluid (e.g.,, atomic/molecular, } \\
\text { micro(nm- } \mu \mathrm{m}) \text {, meso }(\mathrm{mm}) \text {, macro }(\mathrm{mm}-\mathrm{cm})) .)\end{array}$ \\
\hline Flow details & Process condition: Parameters of the flow. (e.g., Reynolds number, velocity, temperature)) \\
\hline Energy/Driving force & $\begin{array}{l}\text { Process condition: in case of both Active and Passive systems, it describes the main force fuelling the } \\
\text { process of separation. (e.g., gravity, gradient of pressure) }\end{array}$ \\
\hline
\end{tabular}

Table 4-1: Specific fields of the GB-BID database for the function "to separate"

Once the fields were identified, the database was populated with biological entries following the general approach proposed in section 3.3. For instance, for the identification of main actions and meaningful synonyms, a final list of verbs was distilled, removing figurative meanings of functions derived from Wordnet (e.g., "captivate", "charm", "conquer"): to separate, divide, filter, extract, excrete, expel, trap, capture, attract, repel, exclude, remove, attach, detach, sediment, precipitate, absorb, adsorb, convert, transform, exchange. With these verbs, the search into biology followed. 
When encoding phenotypes in the relevant fields of the database, the description of biological strategies and mechanisms (often parts of texts extracted from relevant literature) was occasionally reviewed to be more concise and effective than the original text. The authors conducted this exercise themselves in consultations with two biologists when needed. Therefore, the database includes information based on the authors' understanding and intention to propose them in the most clear and precise possible way. The database population was interrupted at 118 phenotypes, as this was considered a suitable number to produce case studies. The diversity of the organisms selected has not been regulated by any specific procedure; however, a certain balance was maintained between organisms from animal and plant kingdoms and different environmental contexts or habitats (seawater, forest, desert, etc.). The database spans from organisms filtering water/air via respiratory systems (gills, lungs) or other dedicated feeding/digesting organs to plants and insects utilising philic-phobic properties via surface micro/nano morphologies. Not all the fields of the database could be filled in and a qualitative estimate was made by the authors, based on similar strategies and contexts for which details were available (e.g., range of size of particles, flow regime, process diagram). Some preliminary statistics are listed below:

- 118 phenotypes of which 40 identified through Asknature.org;

- Animals: 85; plants: 25; bacteria: 2, eukaryote cell: 5; fungi: 1;

- Active/Passive strategy: $65 \%$ of the organisms deploy active strategies and $35 \%$ passive ones;

- Energy: $45 \%$ of the organisms utilize dynamic pressure gradients; $25 \%$ use surface energy (associated with gravity or pressure gradients); $15 \%$ use metabolic energy; $15 \%$ use chemical potential/osmosis/gradient of concentration.

Sub-functions characterising the separation mechanism have been also identified. This not only enriches the description of the process but also acts as connecting functions with future GB-BID databases related to different sector-functions. For instance, in many of the biological mechanisms identified, the functions "move fluids" or "manage fluids" or "exchange heat" or "reduce adhesion" have been classified. This 
allows utilising the database also for solving problems related to functions different from "separate", such as "reduce adhesion", "heat exchange" and "move fluids".

\section{Examples of application}

For each case study, the approach followed has been the typical problem-driven stepped-approach of BID methods as described in Table 2-1, with the only difference being the GB-BID database used as a source of biological solutions for steps 3 and 4 of the process.

\subsection{Sector/Sub-sector case studies.}

With 118 biological entries, it was possible to query the database to initiate the identification of clusters of biological solutions: processes, strategies and mechanisms that nature evolved recurrently to solve problems related to separation.

\section{Separation processes and principles}

Consulting the database's fields "medium" and "main object", it was found that all types of separation (liquid-gas, liquid-solids, etc.) can be retrieved in nature (see examples in Table 5-1).

\begin{tabular}{|c|c|c|}
\hline Type of Separation & N. of entries & Example of Biological solution \\
\hline Liquid-Solids & 45 & Basking Shark's gills trap particles from water \\
\hline Liquid-Liquids & 6 & Fidneys extract water and urea from blood \\
\hline Liquid-Molecules & 30 & Namibian desert beetle hydrophilic surface condenses air moisture \\
\hline Gas-Liquids & 32 & Spider web traps particles/insects from air \\
\hline Gas-Solids & 7 & Respiratory system extracts oxygen from air \\
\hline Gas-Gas & 3 & \\
\hline
\end{tabular}




\begin{tabular}{|c|c|c|}
\hline Solid-Gas & 1 & Plant Roots extract gases from soil \\
\hline Solid-Liquids & 2 & Plant Roots extract water from soil \\
\hline Solid-Solids & 1 & Bacteria extract minerals from rocks \\
\hline
\end{tabular}

Table 5-1: Number of entries of biological solutions in the database for each type of separation process and examples. The total number is more than 118 as some solutions can carry out more separation processes.

Exploring the field "separation principles", the following main separation processes have been identified: phase change (19\%), membrane diffusion (27\%), cross-flow filtration (10\%) and dead-end filtration $(29 \%) . \%)$. It is striking, but perhaps not surprising, the rare occurrence in nature of processes similar to depth filtration (3\%) though this type of filtration is widely used in current separation technology. Depth filtration requires the replacement of the filtering medium when retention performance is no longer achieved. Replacing the medium when clogged would put the organism's life at risk and require considerable metabolic energy. Therefore, in nature, depth filtration is rather conceived as bi/tridimensional meshes and appendages spread with mucus that traps that traps particles. The mucus on appendages is continuously produced. Once saturated with particles, it is directed toward the oesophagus of the organism and phagogitated as food. In several organisms also meshes are continuously produced and phagogitated with the trapped particles.

\section{Separation strategies and mechanisms}

The field "short description of the mechanism" was filtered in search of more clusters of solutions. The following biological separation mechanisms and their structures were identified, including their frequency of occurrence (robustness) within the database.

- Use of cross-flow filtration. Rare occurrence of backwashing via pulsation of filtering system or "coughing"((e.g., Basking shark feeding process through gill rakers (49)). Frequency: 10\% 
- Separate by transforming/changing phase at ambient conditions. Mainly condensation/evaporation processes and chemical reactions (e.g., camel nasal turbinates facilitate air moisture condensation (37)). Frequency: $8 \%$

- Separation by inertial impact/direct interception/diffusion on mesh fibres. In nature, sieving seems rather a problem as it can damage the mesh of the filtering system (e.g., salps (50)). Frequency: 15\%

- Use of mucus or adhesive substance on meshes or surfaces to withhold particles. Hydrosol/hydrogel filtration. Depth filtration process with frequent reuse of filter media as mucus is digested with particles as food (e.g., tunicates (51)). Frequency: $12 \%$

- Continuous self-assembling and renewal of clogged meshes. Clogged meshes are digested as food (e.g., gastropod (51)). Frequency: $4 \%$

- Separation process and flow management via surface morphology (e.g., shark's skin's oleo-phobicity in water (42), moisture condensation on cacti thorns (52), wettability regulation of leaves (53)). Frequency: $20 \%$

- Use of forms to regulate flows passively. Maintenance of laminar flow and management of turbulence via hydrodynamic macro-micro morphologies((e.g., Basking shark mouth (49), shark's skin (42)). Frequency: $20 \%$

To demonstrate the applicability of the database at this level of definition of the problem, the following example is proposed in Table 5-2:

\begin{tabular}{|l|l|}
\hline \multicolumn{2}{|l|}{ Example of applicability of the GB-BID database at sector/subsector level } \\
\hline Problem & $\begin{array}{l}\text { In Reverse Osmosis desalination systems, spiral wound membranes need to be kept separated (to allow } \\
\text { seawater to flow between them) and to generate micro turbulences to avoid concentration polarisation. }\end{array}$ \\
\hline Current solutions & $\begin{array}{l}\text { Spacers (polymeric nets) introduced between membranes to carry out the above-mentioned functions. } \\
\text { Due to their shape, biofouling occurs in the "dead areas" of spacers reducing filtration efficiency. }\end{array}$
\end{tabular}




\begin{tabular}{|l|l|}
\hline Function & To keep two surfaces separated (of fraction of $\mathrm{mm}$ ) and generate micro turbulences along the surface. \\
\hline GB-BID extracted & Querying for available keywords, such as "manage liquids", "on surface" and "passively", the GB-BID \\
& $\begin{array}{l}\text { points at entries providing extracted design principles such as generating micro turbulences via surface } \\
\text { micro-textures (micro-grooves/pillars). The same design principle could also satisfy the function of } \\
\text { keeping two surfaces separated. }\end{array}$ \\
\hline solution & Remove spacers and substitute with micro-pillars built on the membrane's surface. \\
\hline
\end{tabular}

Table 5-2: Example of applicability of the GB-BID database at sector/subsector level - spacers in reverse osmosis membranes

\section{$\underline{\text { Taxonomies of strategies and mechanisms }}$}

The database allows to generate taxonomies of biological solutions organised according to problems of separation expressed in terms of "action", "object", "object property" and some relevant "process conditions". For instance, the database can be filtered according to the keywords as per Table 5-3:

\begin{tabular}{|l|l|l|}
\hline \multicolumn{1}{|c|}{ Action } & \multicolumn{1}{|c|}{ Object, Object property } & \multicolumn{1}{c|}{ Process Condition } \\
\hline Separate & lons/molecules/gasses & Air; liquids \\
\hline Extract & Water vapour & Air \\
\hline Attract/Repel & Water droplets (rain, fog, dew) & Air \\
\hline Repel & Apolar fluids (oil) & Air; liquids \\
\hline Separate/Filter & Particles (microns) & Liquids; laminar flow \\
\hline Separate/Filter & Particles (mm-cm) & Liquids; turbulent flow \\
\hline
\end{tabular}

Table 5-3: example of keywords to develop taxonomies on separation.

For each of the above problems, biological mechanisms were identified and divided between active (requiring metabolic energy) and passive (using available free energy). The biological mechanisms belonging to these two categories were subsequently grouped by type of separation process and by the mechanism which they have in common. 
The mechanisms are shortly described and their frequency of occurrence within the specific separation problem they belong to, has been estimated. In Table 5-4, three examples are extracted for different problems.

\begin{tabular}{|c|c|c|c|c|c|c|}
\hline $\begin{array}{l}\text { Function } \\
\text { (Problem) }\end{array}$ & $\begin{array}{l}\text { Active/ } \\
\text { Passive }\end{array}$ & Process & Biological Mechanism & $\begin{array}{l}\text { Some details of the } \\
\text { mechanism }\end{array}$ & $\begin{array}{l}\text { Example of } \\
\text { Phenotype }\end{array}$ & $\begin{array}{l}\text { Frequency } \\
\text { within the } \\
\text { function }\end{array}$ \\
\hline $\begin{array}{l}\text { Separate } \\
\text { Particles } \\
\text { ( } \mathrm{mm}-\mathrm{cm} \text { in } \\
\text { size) from } \\
\text { fluids } \\
\text { Turbulent flow }\end{array}$ & $\begin{array}{l}\text { Active } \\
\text { Pumping of } \\
\text { water } \\
\text { though } \\
\text { separating } \\
\text { structure }\end{array}$ & $\begin{array}{l}\text { Surface dead- } \\
\text { end }\end{array}$ & $\begin{array}{l}\text { Use of 2D meshes, 3D } \\
\text { strainers. } \\
\text { Mesh created when } \\
\text { needed by intertwined } \\
\text { or overlaid lamellar } \\
\text { structures on 2D or 3D. }\end{array}$ & $\begin{array}{l}\text { Hydrodynamic pressure used } \\
\text { to orient the filaments of the } \\
\text { filtering mesh and regulate } \\
\text { porosity. } \\
\text { Particle direction and sorting } \\
\text { guided by turbulences through } \\
\text { the mesh. }\end{array}$ & $\begin{array}{l}\text { Duck's bill, } \\
\text { Flamingo's bill, } \\
\text { Bowhead } \\
\text { whale baleens. }\end{array}$ & $57.14 \%$ \\
\hline $\begin{array}{l}\text { Separate } \\
\text { Particles } \\
\text { (microns in } \\
\text { size) from } \\
\text { fluids } \\
\text { Laminar/turbul } \\
\text { ent flow }\end{array}$ & $\begin{array}{l}\text { Active } \\
\text { pumping of } \\
\text { water } \\
\text { though } \\
\text { separating } \\
\text { structure }\end{array}$ & $\begin{array}{l}\text { Surface dead- } \\
\text { end: } \\
\text { Sieving/Sorting } \\
\text { with grooves }\end{array}$ & $\begin{array}{l}\text { Sieving/sorting of } \\
\text { particles by grooves } \\
\text { with variable section. } \\
\text { Sometimes assisted by } \\
\text { cilia }\end{array}$ & $\begin{array}{l}\text { V-shaped grooves with various } \\
\text { average width (1-3 } \mu \mathrm{m}) \text { and } \\
\text { sometimes with stepped sides } \\
\text { to select/sort and guide } \\
\text { particles. }\end{array}$ & $\begin{array}{l}\text { Bivalves } \\
\text { feeding } \\
\text { system. }\end{array}$ & $5.71 \%$ \\
\hline $\begin{array}{l}\text { Attract/Repel } \\
\text { water droplets } \\
\text { (rain, fog, dew) }\end{array}$ & $\begin{array}{l}\text { Passive } \\
\text { Surface } \\
\text { energy/ } \\
\text { roughness/ }\end{array}$ & $\begin{array}{l}\text { Coalescence of } \\
\text { droplets/ } \\
\text { Hydrophilicity/ } \\
\text { phobicity }\end{array}$ & $\begin{array}{l}\text { Nano/micro grooves, } \\
\text { ridges and/or } \\
\text { hierarchical structures } \\
\text { on surfaces (pillars) }\end{array}$ & $\begin{array}{l}\text { Near-random array of bumps } \\
0.5-1.5 \mathrm{~mm} \text { apart, each about } \\
0.5 \mathrm{~mm} \text { in diameter. The peaks } \\
\text { of these bumps (about } 100 \mu \mathrm{m}\end{array}$ & $\begin{array}{l}\text { Namibian } \\
\text { Beetle elytra, } \\
\text { Cactis' spines, }\end{array}$ & $33.3 \%$ \\
\hline
\end{tabular}




\begin{tabular}{|l|l|l|l|l|l|}
\hline & Laplace & & gathering and moving & in diameter) are hydrophilic, & Cribellate \\
pressure & fluids & spider net. & super-hydrophobic. \\
\hline
\end{tabular}

Table 5-4: Example of three extracts from taxonomy of separation problem.

Following the above preliminary analysis across the database, it seems that nature does not offer any radically new separation process that human beings did not invent already; however, for each separation process, it deploys interesting, contextualised strategies and mechanisms from which one can draw inspiration.

\subsection{Context-Driven case studies}

Two case studies are described to illustrate the applicability of the database at this level of abstraction of the problem. The first one clearly relates to an application for the separation technology sector (desalination process); the second one (an antibacterial surface), even if at first glance does not seem related to a separation technology, can be considered as such through a process of abstraction.

Both case studies have been developed within the business environment of Planet s.a.s, a start-up dedicated to bio-inspired innovation and through which the opportunities for developing the case studies were generated.

\subsubsection{The Mangrove Still - Desalination system for land regeneration}

The specific problem addressed was: how to produce fresh water in drylands with abundance of saline water and use it to activate land regeneration practices? 
The problem-driven approach (as per Table 2-1) was followed. The process was reiterated, from a systemic perspective of the problem to a technological one.

Problem Definition: land degradation directly affects the productivity of important crops, contributing to major losses in agricultural food production and affecting agricultural sustainability (54). In drylands, land degradation is caused by wind erosion and salinisation, loss of organic substances, sealing and compaction exacerbated by bad land management practices with consequent loss of productive soil and vegetation. Revegetation is one of the most effective means to control soil degradation and to rehabilitate degraded lands and to revegetate, an adequate water content of soil becomes crucial. If in drylands fresh water is scarce and not enough to enable sustainable land management practices, in many of them there is an abundance of saline water, either because they are located in seawater coastal areas or because of the presence of salty lakes and brackish groundwater (55). For these areas, saline water desalination seems to be a logical solution. Despite several desalination technologies available, their costs (capex and opex) are still too high to justify the widespread use of the water produced for agriculture; let alone for regenerating degraded soils.

Problem reframed and Biological Search: the initial search into the GB-BID database was carried out for phenotypes that could answer questions such as "How does nature desalinate?" and "How does nature remove/filter ions/molecules/gasses?". This produced a list of 26 phenotypes. The selection, however, was considered too broad as many strategies were not relevant to the context of the problem. Adding the context to the question such as: "how does nature desalinate to generate ecosystems in drylands?", the selection was narrowed to seven phenotypes operating in contexts similar to the one of the challenge: halophytes plants in general (roots, tissues, salt glands), Mangrove trees (roots, leaves), and Salicornia (tissue). 
Aside from the mechanisms of desalination deployed by these organisms, it appeared relevant to understand the role of desalination within the overall process of setting up an ecosystem. All the organisms selected grow in seawater in coastal ecosystems, such as mangroves and salt marshes. From the analysis of these ecosystems, it emerged that both have pioneer species (i.e., the Avicennia tree for mangroves and Salicornia for salt marshes), which have adapted to survive in a saline environment. These are the first species to colonise a seawater/coastal environment and therefore represent the initial stage of an upcoming complex ecosystem. They kick-start a progressively self-sustaining process of collecting nutrients and water (for instance, via trapping rare rainfalls, increasing air moisture and reducing evaporation via shading) so as to create conditions conducive to other species to appear, which allow the ecosystem to develop through phases (56). Seen from this perspective, in coastal ecosystems, desalination is only one element of an integrated water resource management system; however, it seems a crucial one; the initial strategy upon which other natural strategies to get fresh water would build upon.

Extracting and applying design principles: from the above considerations, it derives that desalination could be indeed the first process to be considered in seawater coastal areas to obtain fresh water. It can contribute to the initial formation of soil and growth of plants, with consequent medium/long term activation of other natural mechanisms to gather and store fresh water as the ecosystem builds up.

As the Avicennia tree is a pioneer species kick-starting an ecosystem, is there a pioneer desalination technology that could do the same? Due to the low level of tech involved and its low production and operation costs, the Solar Still technology was considered. Solar stills systems have been already used for desalinating seawater to produce drinking water on a small scale for families or small villages in developing countries and remote islands. This technology, modular, could be multiplied so as to provide water to an expanding community (57). However, to the best knowledge of the authors, its utilisation to produce water for the land has not been attempted yet. 
Reiterated Problem Definition: the BID process was therefore reiterated targeting a different problem: how to improve the design of the solar still and adapt it to solve the initial problem. Different designs for solar stills have been developed and tested in the last thirty years in order to increase their efficiency (58). Many of them remain at the experimental level because of the complexity of their design or because their costs are not affordable for poor communities. The commercialisation of a few of them has been attempted, but because of the selling price compared to the daily water production $\left(400-1000 \$ / \mathrm{m}^{2}\right)$, there is virtually no market for solar stills.

Problem reframed and biological search: to maximise its yield (L/day $/ \mathrm{m}^{2}$ of distilled water), a solar still has to optimise its evaporation/condensation process. Therefore, the GB-BID database was consulted this time with the following reframed problem: "how does nature collect moisture?". Organisms dealing with a separation strategy using evaporation/condensation process were selected using keywords such as "extract" /"trap" in the "main action" and "sub-action" fields as well as "moisture"/water vapour" in the "object" fields. The database produced a list of 13 phenotypes. Some examples are shown in Table 5-5.

\begin{tabular}{|c|c|c|c|c|c|c|}
\hline $\begin{array}{l}\text { Biological } \\
\text { Organism }\end{array}$ & Phenotype & $\begin{array}{l}\text { Main } \\
\text { Action }\end{array}$ & Object & Medium & Short description of mechanism & $\begin{array}{l}\text { Active/ } \\
\text { Passive }\end{array}$ \\
\hline Orchids & Roots & Trap & Water/moisture & air & $\begin{array}{l}\text { Water interception and Fast absorption by } \\
\text { capillarity }\end{array}$ & PA \\
\hline Tillandsia & Leaves & Extract & Moisture & air & $\begin{array}{l}\text { Water interception via narrow structures } \\
\text { reducing boundary layer and with turbulences }\end{array}$ & PA \\
\hline Camel & $\begin{array}{l}\text { Respiratory } \\
\text { system }\end{array}$ & Extract & Water/moisture & air & $\begin{array}{l}\text { Phase change - evaporation/condensation, } \\
\text { hygroscopic material }\end{array}$ & AC \\
\hline Tick & mouth & Extract & Moisture & air & Hydrophilicity/Hygroscopicity & $\mathrm{PA}$ \\
\hline Thorny devil & Body surface & Extract & Water/moisture & soil/air & Capillarity & PA \\
\hline
\end{tabular}


Table 5-5: Result from filtering the GB-BID database in the fields "main action" and "object" using respectively keywords:

extract/trap - moisture/water vapour. Also indicated a process attribute: Passive (PA)/Active (AC).

Extracting design principles: almost all the found organisms operate in similar contexts of the problem (drylands). From the above phenotypes, specific mechanisms/principles were extracted, such as:

1. Increase of surface/volume ratio to increase evaporation and condensation surfaces;

2. Micro/nano textured surfaces to manage surface tension and produce hydrophilic/phobic behaviour to coalesce moisture from the air;

3. Capillarity to trap water and move it against gravity;

4. Hygroscopic materials to absorb air moisture.

All the above mechanisms operate passively without the use of additional external sources of energy.

Applying the design principles - the Mangrove Still and the Mangrove Technology Platform:

Aside from the use of the extracted design principles the solar still needs to satisfy requirements to increase its efficiency, sustainability and marketability. These requirements are: i) maximise the use of free energy (Sun, gravity); ii) be modular; be light but sturdy;; iii) be easy to assemble, dismantle and operate; iv) be made of material that can be easily found locally and recyclable; v) allowing for the recovery of salt and finally vi) it must be affordable for low-income communities.

Applying the above requirements led to several design concepts and prototypes that were developed and tested till the solution highlighted in Figure 5-1. The modular solar still developed was named Mangrove Stills (in reference to the main biological analogy with the Mangrove ecosystems). Below, some details on the unit: 
Internal structure: aluminium plate $(16 \times 89 \mathrm{~cm})$ painted black; cotton dark textile strip $8-10 \mathrm{~cm}$ high and 90 $\mathrm{cm}$ long as wick material attached and sustained by cellulose sponge bricks. Additional smaller strips of textile were located at the sides of the plate to increase further the evaporation surface.

External structure: triangular section; cover material made in PET sheet $(0,25 \mathrm{~mm})$; side closures made in transparent PMMA; external cover tightens to the side closures via a textile strip with Velcro ${ }^{\mathrm{TM}}$.

A system of 10 units was assembled to be tested. The system (see Figure 5-1) operates in the following way: Salty water path: the system works in batches. The saline water is pre-heated in a black pipe before being fed into a central pipe that distributed the water into the units. The level of water in the unit is around 2-3 $\mathrm{mm}$. Salty water is also absorbed by capillarity through the sponges and the textile increasing the surface area of evaporation by $50 \%$. The overflow (brine) is collected in external aluminium plates where it slowly evaporated, producing salt crystals.

Distilled water path: the water condensed on the internal surface of the transparent cover, dripped along the surface, reaching the lower apex of the triangular structure. The upper apex is positioned in such a way as avoid to avoid drops of condensate in the upper apex not to fall back into the evaporation plate. The condensate is then collected at one side of the unit and drained away by pipes. Finally, a distilled water tank collects all the water produced by the system.

Rainwater collection: the base of the system is enclosed in a plastic foil, so as to gather water from rain which is mixed with the distilled water so as to increase the overall water production.

In order to emulate further the process of building up a natural ecosystem in a saline water environment (such as that of the mangroves),) the desalination system was tested in combination with organic incubators. An organic incubator is a mat $(50 \times 50 \times 10 \mathrm{~cm})$ made of organic fibres (it was originally commercialised as soundproof material for the construction sector), which can act as a nutritional matrix 
for plants and also be inoculated with additional nutrients or fungi that assist the development of plant roots and withhold water.

The overall system, scalable, adaptable and able to integrate and enable other fresh water-based technologies dealing with soil regeneration and revegetation, was named Mangrove Technology Platform.

To start testing and initial pilot combining these two technologies, a Mangrove Still system and two organic incubators were set up in Akrotiri (Cyprus) in March 2018 and tested till July 2018. The tests showed an average production per unit of around $0.5-0,6 \mathrm{~L} /$ day leading to a production of around $5 \mathrm{~L} /$ day of the whole system (of $1 \mathrm{~m}^{2}$ of the evaporating surface). This, however, should take into consideration that the feed water was brine that came from a salt marsh with a salt concentration of around $70 \mathrm{gr} / \mathrm{L}$.

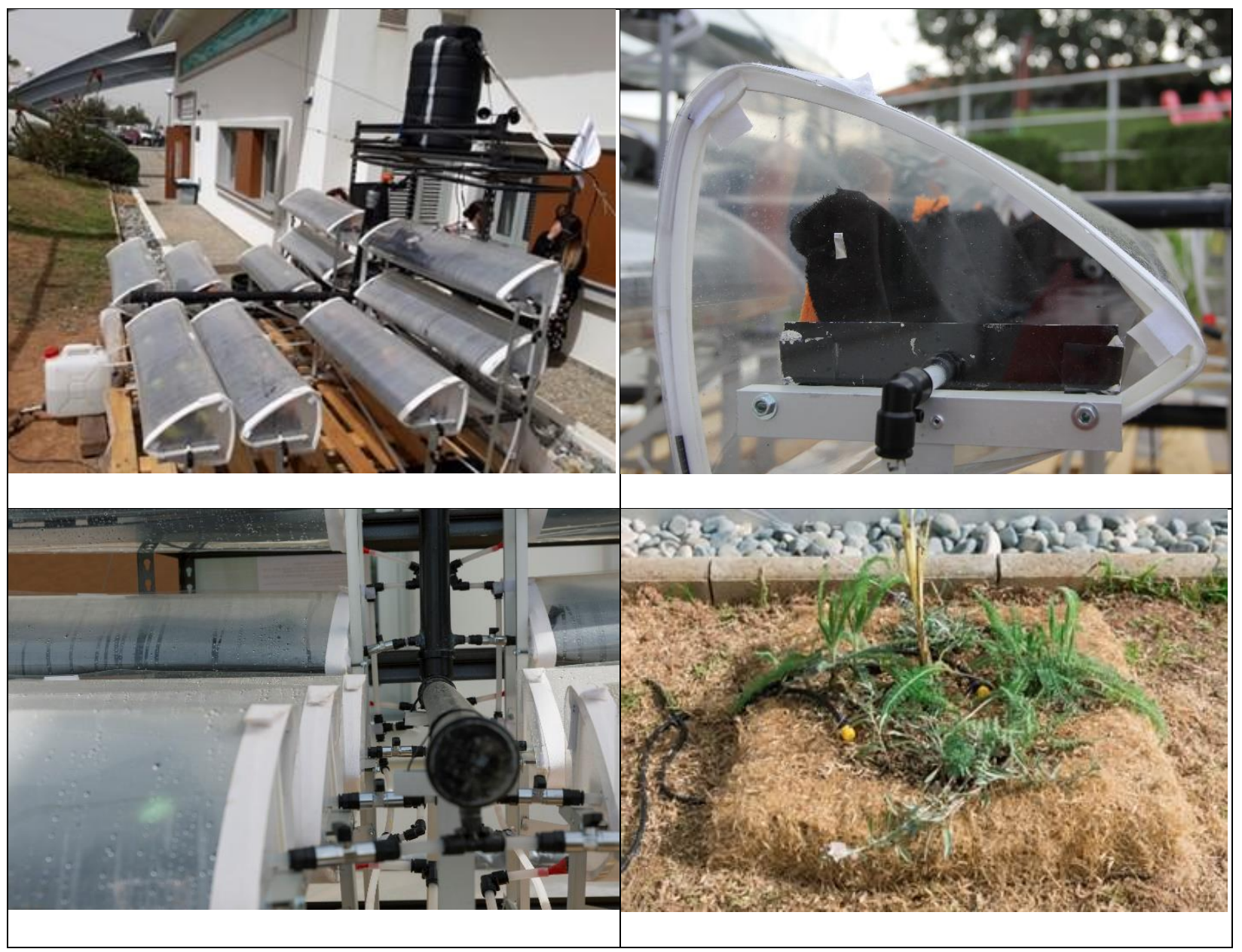


Figure 5-1: (upper left) Mangrove Still (MS) system in Akrotiri; (upper right) a particular of the inside of the MS unit. (lower left) central pipe distributing salt water to the units; (lower right) the organic incubator with plants irrigated by water produced by MS system.

\section{Discussion on the Mangrove Still case study}

Even though it is still at its pilot testing phase, the design concept developed appears to be competitive with other existing similar products, some of which are already on the market. Through a search online about existing commercialised solutions (brands such as Aquamate, Rainmaker, Cleardome were identified), it appears that current solutions are positioned in a range of $150-300$ US\$ per L/day of average water produced. The Mangrove Still system is currently in the range of 100 US\$. Furthermore, the utilisation of commonly available materials and the simplicity of design do not require specially designed equipment or tools to assemble the units.

Understanding the organism (the mangrove tree) and its strategy within the broader context of the ecosystem it belongs to (the Mangrove ecosystem), allowed to extract a design principle that relates to an improvement of desalination technology, but rather to a change in its applicability: from producing drinking water for human consumption, to producing water for the land. This could open up new design concepts for a solar still and market opportunities previously not explored. In particular, the Mangrove Technology Platform can inspire creating consortia of existing and new products and technologies operating in synergy toward the common goal of regenerating degraded lands and revitalising ecosystem services. This would tap into a rather new market sector - that of land regeneration - still in its infancy but already in high demand in connection with sustainable food production, carbon sinks and biodiversity preservation. 


\subsubsection{Bio-Cover - Antibacterial surface}

The specific problem addressed was: How to reduce the settlement of bacterial colonies (bio-films) on surfaces exposed to air

Problem Definition: the control of bacterial growth on surfaces in order to reduce the risk of infections is generally tackled by activating preventive measures, such as hygiene practices and utilising "kill" technologies including antibiotics, disinfectants and dangerous chemicals (containing silver ions that can poison and be harmful to the environment). However, kill strategies and their overuse have led to subsequent increased bacterial resistance, causing further harm to people and the environment. There is therefore the need for a cheaper but effective way to protect people from infections without causing harm to the environment and without risking the creation of new generations of resistant bacteria (59).

The following factors can play a role in bacteria adhesion on surfaces: surface charge, hydrophobicity, roughness, topography, stiffness and chemistry $(43,60)$. In particular, the exact effects of surface roughness on bacterial adhesion and biofilm formation vary with the size and shape of bacterial cells and other environmental factors (61). Many engineered micro-nano scale topographic patterns with varying shapes and size have been shown to inhibit biofilm formation compared to flat surfaces of the same material $(43,62)$. The reasons behind this inhibition are not yet fully understood, but shapes and distances in the surface's features (such as cones, pillars and ridges) equal to or significantly smaller than the bacteria's dimension may create deformations and ruptures in bacterial membranes and limit their mobility (62). The effect of surface stiffness (which depends on geometry, size of the features and modulus of the material) on bacterial adhesion has not been largely researched yet, but initial results seem to be hinting at a decrease in bacterial growth with an increase of stiffness of the surface's features (60).

Problem reframed and biological search: to the question "How does nature repel/exclude bacteria/water/oil?", the GB-BID database produced a list of 11 phenotypes which included plants, leaves, 
and flowers that possess self-cleaning properties because of the superficial micro-nano patterns on their surfaces, allowing them to manage surface tension and adhesion.

The only reference to antibacterial properties concerns the skin of sharks. Shark's skin is covered by toothlike scales called dermal denticles, ribbed with longitudinal grooves. The denticles are aligned along the body axis and have a diamond-like shape. They are generally formed by V-shaped riblets with variable length (around 130-700 $\mu \mathrm{m})$, width $(70-460 \mu \mathrm{m})$, height $(25-500 \mu \mathrm{m})$ and spacing $(100-300 \mu \mathrm{m})$ depending on the species of shark and the location on its body $(42,63,64)$. The riblets work by impeding the cross-stream translation of streamwise vortices in the viscous sublayer. The mechanism by which the riblets interact with and impede vortex translation is complex, and the entirety of the phenomenon is not yet fully understood $(42,43)$.

The roughness of the denticles also seems to create an unfavourable environment for bacteria to attach. The company Sharklet Technologies conducted tests on antibacterial properties of engineered surfaces mimicking the morphology of dermal denticles, but on a smaller scale. The surfaces were made of microscopic rectangular features $2 \mu \mathrm{m}$ wide and with $2 \mu \mathrm{m}$ spacing, either protruding or carved $3 \mu \mathrm{m}$ arranged in diamond shapes on silicone elastomer layers $(65,66)$. According to these tests, the engineered surfaces can delay the colonisation of biofilms up to 21 days compared to a non-textured surface (66). While searching for a micro pattern which could provide stiffness at that scale, the GB-BID database suggested the convoluted, spiralling micro-ridges (height: 0,4-0,7 $\mu \mathrm{m}$; width: 0,2 - 0,6 $\mu \mathrm{m}$ ) of the epithelial cells of teleost fish gills, reported as providing extra resistance to stresses (67). However, no studies have reported on their possible antibacterial function.

Extracting design principles: from the above two phenotypes identified, the following principles to design potentially antibacterial surface patterns were extracted: 
- V-shaped riblets with variable length (around 130-700 $\mu \mathrm{m})$, width $(70-460 \mu \mathrm{m})$, height $(25-500 \mu \mathrm{m})$ and spacing $(100-300 \mu \mathrm{m})$;

- Micro-ridges with spiralling patterns on a surface to avoid bacterial colonisation.

Applying the design principles: a combination of the two extracted principles was utilised as inspiration to design a micro-texture to be tested for its antibacterial properties (Figure 5-2).

The length (variable from 100 to $550 \mu \mathrm{m})$ and width $(50 \mu \mathrm{m})$ of the segments composing the spiralling geometrical unit are in line with the order of magnitude of the riblets of the dermal denticles of the sharks; their distances $(50 \mu \mathrm{m})$ are proportionate to the distance between the spiralling riblets of the epithelial cells. The height of the riblets is $20 \mu \mathrm{m}$. The textured is an isotropic repetition of the unit, where a pillar has been inserted at the intersection of four units in order to reduce the gap and theoretically prevent bacteria from settling in that space.

A prototype of the mould of the surface was produced via micro-electrical discharge machining (EDM) by a specialised company and samples made in reinforced polypropylene. To conduct the tests, the following sets of micro-textured plaques were produced:

- twelve $5 \times 5 \mathrm{~cm}$ polypropylene (Braskem RCP RP 250 polypropylene) plaque samples with the antimicrobial pattern (Figure 5-2);

- twelve $5 \times 5 \mathrm{~cm}$ polypropylene plaques with smooth control samples moulded from a polished silicon wafer.

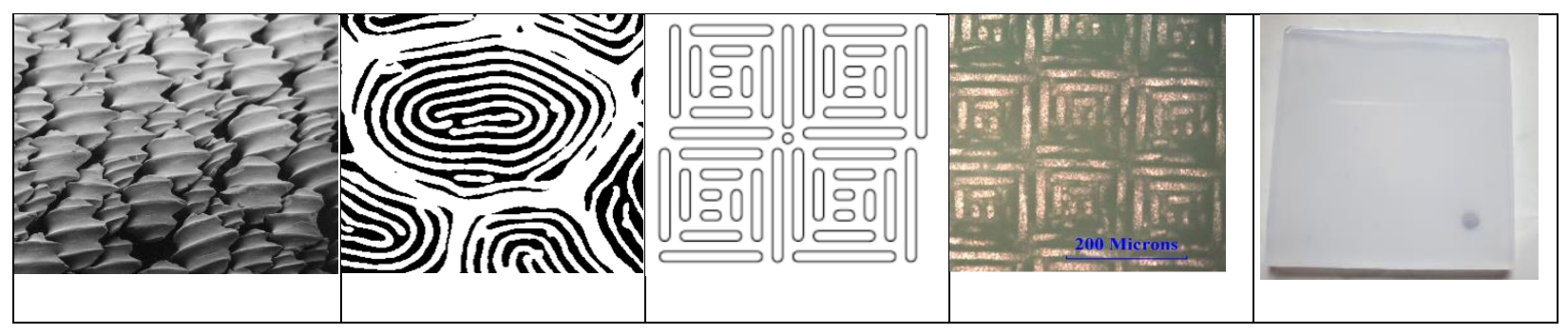




\begin{tabular}{|c|c|c|c|c|}
\hline$a$ & $b$ & $c$ & $d$ & $e$ \\
\hline
\end{tabular}

Figure 5-2: a. Dermal denticles on shark's skin; b. Sketch of shape of epithelial cell's of Teleost fish's gill; c. Bio-cover design; $d$. detail of the textured plaque in reinforced polypropylene (PPT40); e. Plaque $5 \times 5 \mathrm{~cm}$ in PPT40.

The antibacterial test was designed and conducted by a certified lab applying ISO17025 standards. For 60 days, the samples were immersed in water at $20-28{ }^{\circ} \mathrm{C}$ with the following bacteria: Coliform, E Coli, St. Aureus, Salmonella, Listeria, Enterococcus and Pseudosomonas Aeruginosa. The calculation of bacteria on the plaques with the pattern, on the ones without (control) and in the blank sample (water with no plaques) was performed three times at three different time intervals (on the same material samples) on the 7th, 15th, 30th and 60th day. The experiment showed a delay in the multiplication of bacteria on the bio-cover for at least 15 days (the order of magnitude of the number of bacteria on bio-cover remained stable compared to the bacteria on the control plaque). After 15 days, as replication of bacteria accelerated on both the control and the test surface textured surface, it was no longer possible to claim any further antibacterial capacity.

\section{Discussion on the Bio-cover case study}

Even if results are not conclusive and further experiments should be undertaken, they are nevertheless promising. The surface pattern, whose design has been inspired by biological solutions present in the GBBID database, shows antibacterial performances comparable to Sharklet's pattern in terms of delaying colonisation of a surface by several types of bacteria. However, different to Sharklet, the bio-cover operates at a scale that is more than one order of magnitude greater with a possible reduction in production costs and an increase in durability. This last one however still needs to be tested. 


\section{Conclusions and limitations}

The potential for bio-inspired innovation is still largely untapped. BID methods and tools are not yet largely utilised, especially within the separation technology industry, a sector with the potential of turning bioinspired ideas into marketable innovation.

Due to its size and high segmentation within the global market and the global challenges driving the need for innovation, this sector could benefit from a bio-inspired approach to create more efficient and sustainable solutions.

A new BID method, called Guild-Based BID, was therefore proposed to create databases of biological information structured in a way to be more effective and usable within the industrial environment for generating bio-inspired ideas.

Aiming at addressing drawbacks such as lack of quantity of relevant biological solutions and effective organization of biological information of other existing BID tools (see section 2.1), the GB-BID method proposes a framework for organising biological information to set up databases of biological solutions related to a main function. These solutions would allow generating bio-inspired ideas for specific industrial sectors. With this approach, the cost of retrieving and storing biological information, typical of BID methods, can be offset by the benefits of:

- having information organised in a meaningful way for a specific industrial sector and not only for a single company. This could stimulate companies operating in the same industry sector (sub-sectors, competitors, or belonging to the supply chain) to share the cost for setting up BID databases as well as sharing its use to generate ideas (i.e. in open innovation framework);

- having a large number of biological solutions for the same main function, which allows identifying biological solutions that are recurrent (and possibly more robust), applicable at different scales and relevant to solve different levels of abstraction of the problem. 
To demonstrate the above, a database for separation technology was set up and tested.

The database was populated with 118 relevant biological solutions responding to the main function "to separate" and was utilised to generate solutions to problems related to separation technology at different levels of abstraction. In particular:

- Broad design principles of separation which can provide valuable indications to steer sectoral research toward innovative solutions.

- Taxonomies of biological solutions for specific separation problems which could be utilised to generate innovative bio-inspired technology.

- Novel design concepts for specific separation technologies with a chance of becoming marketable (the Mangrove Still and Bio-cover) which can open up to new markets that were previously not accessible. The results achieved so far indicate that the GB-BID database for separation technology can be indeed beneficial in generating innovative ideas for the sector.

To demonstrate its efficacy in generating innovative ideas more robustly, especially in comparison with other existing BID methods, and to justify the costs for setting it up, the GB-BID method has to be further tested in a relevant industrial set up; through both idea generation workshops among experts in separation process and those working on specific design challenges related to the problems of separation technology.

Furthermore, as the database was prepared by the authors, who are not biologists, they may have introduced subjective judgement when encoding biological information; this risk should be minimised by having the database reviewed by relevant experts in biology. 


\section{Acknowledgements}

The authors would like to thank Planet s.a.s, in particular Alessandro Villa and Alessandro Zecca who contributed to the development of the Mangrove Still and Bio-cover. The authors would also like to thank Expo Live-Expo 2020 Dubai for providing the funding to carry out the development and pilot test of the Mangrove Still in Cyprus. 


\section{References}

1. Ramsey TH. Filtration \& Separation Industry - A Solutions Driven Industry for the World Around Us.... American Filtration \& Separation Society; 2017.

2. Sutherland K. 50th Anniversary: Half a century of developments in filtration. Filtration + Separation. 2013 Jan;50(1):14-6.

3. Frinton S. Trends that will shape the future of filtration. International Filtration News [Internet]. 2019 Aug 5; Available from: https://www.filtnews.com/trends-that-will-shape-the-future-offiltration/

4. Shen Y, Saboe PO, Sines IT, Erbakan M, Kumar M. Biomimetic membranes: A review. Journal of Membrane Science. 2014 Mar;454:359-81.

5. Peng $Y$, Guo Z. Recent advances in biomimetic thin membranes applied in emulsified oil/water separation. J Mater Chem A. 2016;4(41):15749-70.

6. Ma W, Li Y, Zhang M, Gao S, Cui J, Huang C, et al. Biomimetic Durable Multifunctional Self-Cleaning Nanofibrous Membrane with Outstanding Oil/Water Separation, Photodegradation of Organic Contaminants, and Antibacterial Performances. ACS Appl Mater Interfaces. 2020 Aug 5;12(31):34999-5010.

7. Bonser R, Vincent J. Technology trajectories, innovation and the growth of biomimetics. Journal of Biomechanics - J BIOMECH. 2006 Dec 31;39.

8. Gebeshuber IC, Drack M. An attempt to reveal synergies between biology and mechanical engineering. Proceedings of the Institution of Mechanical Engineers, Part C: Journal of Mechanical Engineering Science. 2008 Jul;222(7):1281-7.

9. Benyus JM. Biomimicry - Innovation Inspired by Nature. Harper Perennial; 1998.

10. Gentner D, Rattermann MJ, Forbus KD. The Roles of Similarity in Transfer: Separating Retrievability From Inferential Soundness. Cognitive Psychology. 1993 Oct;25(4):524-75.

11. Helms M, Vattam SS, Goel AK. Biologically inspired design: process and products. Design Studies. 2009 Sep;30(5):606-22.

12. Helfman Cohen Y, Reich Y. Biomimetic Design Method for Innovation and Sustainability [Internet]. Cham: Springer International Publishing; 2016 [cited 2019 Sep 5]. Available from:

http://link.springer.com/10.1007/978-3-319-33997-9

13. Wanieck K, Fayemi P-E, Maranzana N, Zollfrank C, Jacobs S. Biomimetics and its tools. Bioinspired, Biomimetic and Nanobiomaterials. 2017 Jun;6(2):53-66. 
14. Fu K, Moreno D, Yang M, Wood KL. Bio-Inspired Design: An Overview Investigating Open Questions From the Broader Field of Design-by-Analogy. Journal of Mechanical Design. 2014 Nov 1;136(11):111102.

15. Fayemi PE, Wanieck K, Zollfrank C, Maranzana N, Aoussat A. Biomimetics: process, tools and practice. Bioinspir Biomim. 2017 Jan 23;12(1):011002.

16. Baldussu A, Cascini G. About Integration Opportunities between TRIZ and Biomimetics for Inventive Design. Procedia Engineering. 2015;131:3-13.

17. Chakrabarti A, Sarkar P, Leelavattamma B, Nataraju B. A functional representation for aiding biomimetic and artificial inspiration of new ideas. AIE EDAM. 2005 May; Volume 19.

18. Goel AK, Rugaber S, Vattam S. Structure, behavior, and function of complex systems: The structure, behavior, and function modeling language. AIEDAM. 2009 Feb;23(1):23-35.

19. Helfman Cohen Y, Reich Y, Greenberg S. Biomimetics: Structure-Function Patterns Approach. J Mech Des. 2014 Oct 8;136(11):111108.

20. Chakrabarti A, Siddharth L, Dinakar M, Panda M, Palegar N, Keshwani S. Idea Inspire 3.0-A Tool for Analogical Design. In: Chakrabarti A, Chakrabarti D, editors. Research into Design for Communities, Volume 2 [Internet]. Singapore: Springer Singapore; 2017 [cited 2019 Sep 5]. p. 475-85. Available from: http://link.springer.com/10.1007/978-981-10-3521-0_41

21. Goel AK, McAdams DA, Stone RB, editors. Biologically inspired design: computational methods and tools. London ; New York: Springer; 2014. 325 p.

22. Fermanian Business \& Economic Institute. BIOINSPIRATION: An Economic Progress Report. 2013.

23. Lenau TA, Metze A-L, Hesselberg T. Paradigms for biologically inspired design. In: Lakhtakia A, editor. Bioinspiration, Biomimetics, and Bioreplication VIII [Internet]. Denver, United States: SPIE; 2018 [cited 2019 Sep 5]. p. 1. Available from: https://www.spiedigitallibrary.org/conferenceproceedings-of-spie/10593/2296560/Paradigms-for-biologically-inspireddesign/10.1117/12.2296560.full

24. Jacobs SR, Nichol EC, Helms ME. "Where Are We Now and Where Are We Going?" The BioM Innovation Database. Journal of Mechanical Design. 2014 Nov 1;136(11):111101.

25. Chirazi J, Wanieck K, Fayemi P-E, Zollfrank C, Jacobs S. What Do We Learn from Good Practices of Biologically Inspired Design in Innovation? Applied Sciences. 2019 Feb 14;9(4):650.

26. Lenau TA, Orrù AM, Linkola L. Biomimicry in the Nordic Countries [Internet]. Nordic Council of Ministers; 2019 Jan [cited 2020 Jan 8]. Available from:

http://urn.kb.se/resolve?urn=urn:nbn:se:norden:org:diva-5274

27. Baumeister D, et Al. Biomimicry Resource Handbook: a seed bank of knowledge and best practices. 2011. 
28. Hashemi Farzaneh H, Lindemann U. A Practical Guide to Bio-inspired Design [Internet]. Berlin, Heidelberg: Springer Berlin Heidelberg; 2019 [cited 2019 Sep 5]. Available from: http://link.springer.com/10.1007/978-3-662-57684-7

29. Vincent JFV, Bogatyreva OA, Bogatyrev NR, Bowyer A, Pahl A-K. Biomimetics: its practice and theory. J R Soc Interface. 2006 Aug 22;3(9):471-82.

30. Nagel JKS, Stone RB, McAdams DA. An Engineering-to-Biology Thesaurus for Engineering Design. In: Volume 5: 22nd International Conference on Design Theory and Methodology; Special Conference on Mechanical Vibration and Noise [Internet]. Montreal, Quebec, Canada: ASMEDC; 2010 [cited 2020 Jan 28]. p. 117-28. Available from: https://asmedigitalcollection.asme.org/IDETCCIE/proceedings/IDETC-CIE2010/44137/117/336303

31. Blondel J. Guilds or functional groups: does it matter? Oikos. 2003 Feb;100(2):223-31.

32. Crowley PH, Cox JJ. Intraguild mutualism. Trends in Ecology \& Evolution. 2011 Dec;26(12):627-33.

33. Simberloff D, Dayan T. The Guild Concept and the Structure of Ecological Communities. Annu Rev Ecol Syst. 1991 Nov;22(1):115-43.

34. Thompson JN. The Coevolutionary Process. The Univeristy of Chigago Press; 1994.

35. Balestrieri R, Basile M, Posillico M, Altea T, De Cinti B, Matteucci G. A guild-based approach to assessing the influence of beech forest structure on bird communities. Forest Ecology and Management. 2015 Nov;356:216-23.

36. Wu G, Zhao N, Zhang C, Lam YY, Zhao L. Guild-based analysis for understanding gut microbiome in human health and diseases. Genome Med. 2021 Dec;13(1):22.

37. Schmidt-Nielsen K, Schroter RC, Shkolnik A. Desaturation of Exhaled Air in Camels. Proceedings of the Royal Society of London Series B, Biological Sciences. 1981;211(1184):305-19.

38. Cain A. Taxonomy. In: Encyclopedia Britannica [Internet]. 2020. Available from: https://www.britannica.com/science/taxonomy

39. Vincent JFV, Bogatyreva O, Pahl A-K, Bogatyrev N, Bowyer A. Putting Biology into TRIZ: A Database of Biological Effects. Creativity \& Inn Man. 2005 Mar;14(1):66-72.

40. Helms M, Vattam SS, Goel AK. Biologically inspired design: process and products. Design Studies. 2009 Sep;30(5):606-22.

41. Cascini G, Rissone P. Plastics design: integrating TRIZ creativity and semantic knowledge portals. null. 2004 Aug 1;15(4):405-24.

42. Jung YC, Bhushan B. Biomimetic structures for fluid drag reduction in laminar and turbulent flows. J Phys: Condens Matter. 2010 Jan 27;22(3):035104.

43. Hasan J, Crawford RJ, Ivanova EP. Antibacterial surfaces: the quest for a new generation of biomaterials. Trends in Biotechnology. 2013 May;31(5):295-304. 
44. Nicholson DJ. The concept of mechanism in biology. Studies in History and Philosophy of Biological and Biomedical Sciences. 2012;12.

45. Pahl G, Wallace K, Blessing L, Pahl G, editors. Engineering design: a systematic approach. 3rd ed. London: Springer; 2007. $617 \mathrm{p}$.

46. Hirtz J, Stone RB, McAdams DA, Szykman S, Wood KL. A functional basis for engineering design: Reconciling and evolving previous efforts. Res Eng Design. 2002 Mar;13(2):65-82.

47. Shah JJ, Smith SM, Vargas-Hernandez N. Metrics for measuring ideation effectiveness. Design Studies. 2003 Mar;24(2):111-34.

48. Sutherland K, editor. Filters and filtration handbook. 5. ed. Amsterdam: Elsevier, ButterworthHeinemann; 2008. 523 p.

49. Sanderson SL, Roberts E, Lineburg J, Brooks H. Fish mouths as engineering structures for vortical cross-step filtration. Nat Commun. 2016 Apr;7(1):11092.

50. Deibel D. Feeding mechanism and house of the appendicularian Oikopleura vanhoeffeni. Marine Biology. 1986 Dec;93(3):429-36.

51. Riisgård H, Larsen P. Particle capture mechanisms in suspension-feeding invertebrates. Mar Ecol Prog Ser. 2010 Nov 18;418:255-93.

52. Ju J, Bai H, Zheng Y, Zhao T, Fang R, Jiang L. A multi-structural and multi-functional integrated fog collection system in cactus. Nat Commun. 2012 Jan;3(1):1247.

53. Bhushan B, Jung YC, Koch K. Micro-, nano- and hierarchical structures for superhydrophobicity, selfcleaning and low adhesion. Phil Trans R Soc A. 2009 May 13;367(1894):1631-72.

54. Vrščaj B, Ammann W. Background document: the economics of desertification, land degradation and drought : methodologies and analysis for decision-making. Davos: Global Risk Forum : United Nations Convention to Combat Desertification; 2013.

55. UNEP/GRID-Arendal. Urban, dryland, and polar systems - Map [Internet]. 2007. Available from: https://www.grida.no/resources/6072

56. Alongi D. The Energetics of Mangrove Forests. The Energetics of Mangrove Forests. 2009 Jan 1;1216.

57. Kabeel AE, Hamed AM, El-Agouz SA. Cost analysis of different solar still configurations. Energy. 2010 Jul;35(7):2901-8.

58. Manchanda H, Kumar M. A comprehensive decade review and analysis on designs and performance parameters of passive solar still. Renewables. 2015 Dec;2(1):17.

59. Stone PW. Economic burden of healthcare-associated infections: an American perspective. Expert Review of Pharmacoeconomics \& Outcomes Research. 2009 Oct;9(5):417-22. 
60. Song F, Koo H, Ren D. Effects of Material Properties on Bacterial Adhesion and Biofilm Formation. J Dent Res. 2015 Aug;94(8):1027-34.

61. Ramakrishna SN, Clasohm LY, Rao A, Spencer ND. Controlling Adhesion Force by Means of Nanoscale Surface Roughness. Langmuir. 2011 Aug 16;27(16):9972-8.

62. Laha B, Ghosh M, Chebolu A, Nagahanumaiah. Investigation on bacterial adhesion and colonisation resistance over laser-machined micro patterned surfaces. Micro \&amp; Nano Letters. 2013 Jun 1;8(6):280-3.

63. Ankhelyi MV, Wainwright DK, Lauder GV. Diversity of dermal denticle structure in sharks: Skin surface roughness and three-dimensional morphology. Journal of Morphology. 2018 Aug;279(8):1132-54.

64. Feld K, Kolborg AN, Nyborg CM, Salewski M, Steffensen JF, Berg-Sørensen K. Dermal Denticles of Three Slowly Swimming Shark Species: Microscopy and Flow Visualization. Biomimetics. 2019 May 24;4(2):38.

65. Mann EE, Manna D, Mettetal MR, May RM, Dannemiller EM, Chung KK, et al. Surface micropattern limits bacterial contamination. Antimicrob Resist Infect Control. 2014;3(1):28.

66. Chung KK, Schumacher JF, Sampson EM, Burne RA, Antonelli PJ, Brennan AB. Impact of engineered surface microtopography on biofilm formation of Staphylococcus aureus. Biointerphases. 2007 Jun;2(2):89-94.

67. DePasquale JA. Microridges in Cyprinus carpio scale epidermis. Acta Zool. 2018 Apr;99(2):158-68. 